\title{
Prospective Randomized Controlled Study Evaluating Efficacy of Alpha-Blockers, Antimuscarinics or Combination Therapy in Relieving Ureteral Stent-Related Symptoms
}

\author{
MOHAMED S. EL-DANEEN, M.Sc.; AHMED F. GHAITH, M.D.; MAGED M. RAGEB, M.D. and \\ ABD EL-NASER K. EL-GAMASY, M.D.
}

The Department of Urology, Faculty of Medicine, Tanta University, Tanta, Egypt

\begin{abstract}
Background: Double-J ureteral stent placement is a routine urologic procedure after most of urological interventions. Great efforts are being done to decrease stent symptoms including; improving stent materials, physical properties, and design. Also the application of a combination of alpha-blockers and antimuscarinics are used in our study.
\end{abstract}

Aim of Study: We evaluated the effectiveness and safety of tamsulosin, solifenacin, and combination of both in reducing double-J stent-related lower urinary symptoms.

Patients and Methods: A total of 120 patients with double$\mathrm{J}$ ureteral stenting were randomly divided, post-operatively, into 4 groups. In Group A ( $\mathrm{n}=30)$, tamsulosin $0.4 \mathrm{mg}$ was given, Group B $(n=30)$ received solifenacin $10 \mathrm{mg}$ daily, Group $\mathrm{C}(\mathrm{n}=30)$ received solifenacin $10 \mathrm{mg}$ and tamsulosin $0.4 \mathrm{mg}$ daily, and Group D $(n=30)$ received placebo (control group). Two weeks after discharge was the first time of evaluation (pre-treatment assessment), using an arabic validated version of USSQ. The second visit was after 4 weeks from surgery just before stent removal (post-treatment assessment).

Results: There were statistical significance in urinary symptoms, pain, general health and work performance scores in favour of Group III as compared to the tamsulosin group, the solifenacin group, and the control group ( $p$-value $<0.001$ )

Conclusion: Combined therapy of tamsulosin and solifenacin significantly alleviated symptoms associated with double-J stents as compared to either medication alone.

Key Words: Alpha blockers - Antimuscarinics - Combination - Double-J symptoms.

\section{Introduction}

DOUBLE-J ureteral stent placement is a routine urologic procedure after most of urological interventions. D-J stent helps to control many complications as ureteral edema, extravasation, and peforation to avoid later stricture. We report the

Correspondence to: Dr. Mohamed S. El-Daneen, E-Mail: mohamedeldaneen@yahoo.com incidence Urinary symptoms and pain (flank and suprapubic) associated with stenting. Also there are deterioration in general health and work performance and affection of the sexual performance. The discomfort from placement of the stent, however, occurs significantly in some patients. The studies reported the incidence of frequency $(50 \%$ $60 \%$ ), urgency $(57 \%-60 \%)$, dysuria $(40 \%)$, incomplete emptying (76\%), flank (19\%-32\%) and suprapubic pain $(30 \%)$, and hematuria $(25 \%)$ [1]

Great efforts are being done to decrease stent symptoms including; improving stent materials, physical properties, and design. Also the application of a combination of alpha-blockers and antimuscarinics are used in our study [2]

Tamsulo sin acts as a selective inhibitor of $\alpha$ $1 \mathrm{a} / 1 \mathrm{~d}$ mediated contraction of the smooth muscles in distal ureter, bladder trigone, and bladder neck. It is thought that relaxing these smooth muscles decreases bladder outlet resistance and voiding pressure, with beneficial effect on stent [3]

Solifenacin acts as a muscarinic receptor antagonist used for treatment of patients with Overactive Bladder $(\mathrm{OAB})$ and might be effective as well for stent related symptoms [4].

In this prospective study we evaluated the effectiveness and safety of alpha- 1-blocker (tamsulosin), antimuscarinic (solifenacin), and combination of both medications in reducing double- $\mathrm{J}$ stent-related LUTS, using the Arabic version of USSQ [5].

\section{Patients and Methods}

This study was carried out in Tanta University Hospitals during the period from January 2017 to 
January 2018. After hospital Ethical Committee approval and written informed consent, 120 patients were included in the study according to exclusion and inclusion criteria with ureteral stent insertion after ureteral surgeries for a variety of reasons. There was a code number for every patient's file. Complete history taking, physical examination and routine laboratory and radiological investigations for the patient were done.

Inclusion criteria: All adult patient who underwent ureteral stent insertion after ureteral surgeries for a variety of reasons.

\section{Exclusion criteria:}

1- Pediatric patients less than 18 years old.

2- Patient with bleeding tendency.

3- Patient with neurogenic bladder.

4- Patient with bladder outlet obstruction.

All patients were be randomly assigned into four treatment groups by the block randomization method which is designed to randomize subjects into groups that result in equal sample sizes. The resulted group assignment were;

Group A: Included code numbers from 1 through 30 whom took alpha blocker in the form of (tamsulosin $0.4 \mathrm{mg}$, tablet as a single dose at bed time).

Group B: Included code numbers from 31 through 60 whom took antimuscarinic in the form of (solifenacin $10 \mathrm{mg}$, tablet once daily).

Group $C$ : Included code numbers from 61 through 90 whom took alpha blocker (tamsulosin) and antimuscarinic (solifenacin).

Group D: Included code numbers from 91 through 120 whom took placebo (in the form of starch tablet once daily).

All the stents were placed by senior staff, stent introduced with an appropriate length according to mathematic formula; length $=0.125 \mathrm{X}$ body height in $\mathrm{cm}+0.5 \mathrm{~cm}$, positioning verified at the completion of surgery. $16 \mathrm{Fr}$ urethral catheter was fixed for 1 to 2 days postoperatively. In the first postoperative day a KUB film was done to confirm position of the DJ stent. Injection antibiotics used according to urine culture and antibiotic sensitivity besides NSAIDs for analgesia. After discharge suitable antibiotic and analgesic were prescribed in oral forms taken for 7 days.

Two weeks after discharge was the first time of evaluation (pre-treatment assessment), all patients asked to come again into the hospital to assess stent related symptoms using an Arabic validated version of USSQ, which evaluates stentrelated morbidity in six sections, including urinary symptoms, body pain, general health, work performance, sexual matters , and additional problems. Each section comprises several questions the answers of which are summed to allocate a score. The calculation of the score for each section provides the urinary index score, pain index score, general health score, work performance score, and sexual matters score. The second visit was after 4 weeks from surgery just before stent removal and after 2 weeks of treatment with the tested drugs, the same USSQ items of the first visit were evaluated according to patient experience in the 2 weeks of treatment with tested drugs (post-treatment assessment).

\section{Statistical analysis:}

Chi-square test: For categorical variables, to compare between different groups.

F-test (ANOVA): For normally distributed quantitative variables, to compare between more than two groups, and Post Hoc test (Tukey) for pairwise comparisons.

Kruskal Wallis test: For abnormally distributed quantitative variables, to compare between more than two studied groups, and Post Hoc (Dunn's multiple comparisons test) for pairwise comparisons.

Mean/average: Sum of all values divided by the number of values.

Standard deviation ( $S D)$ : Indicates how much a set of values is spread around the average.

The $p$ (probability) value: Gives the probability of any observed difference having happened by chance. The lower the $p$-value, the less likely it is that the difference happened by chance and so the higher the significance of the finding. $p=0.01$ is often considered to be "highly significant".

\section{Ethical considerations:}

There are adequate provisions to maintain privacy of participants and confidentiality of the data as every patient had a code number, the name and the address were kept in a special private file linked to the research, the results of the study were used only for scientific purpose and not for any other purposes. The ethical committee approval was taken under the number ( ) also an informed consent was obtained from all participants in this research after full explanation of benefits and risks of the study. 


\section{Results}

A total of 120 patients were enrolled in the study, and 107 patients completed the study (3 patients from Group A, 4 patients from Group B, 2 patients from Group C, and 4 patient from Group D dropped out). Group A (27 patients) consisted of 14 men and 13 women (mean age: $49.44 \pm 12.59$ SD), Group B (26 patients) consisted of 13 men and 13 women (mean age: $46.65 \pm 13.05$ SD years), Group C (28 patients) consisted of 15 men and 13 women (mean age: $45.96 \pm 9.43$ SD years), and Group D (26 patients) consisted of 16 men and 8 women (mean age: $48.81 \pm 10.73 \mathrm{SD}$ years). The main indication of ureteral double-J stent placement was URS and ESWL. All patients completed the necessary questionnaires. There were no statistically significant differences between groups regarding patient's demographics and treatment indications (Table 1). Therapies were well tolerated, and no patients discontinued the treatments because of side effects. When comparing the pretreatment and post treatment scores, we found that there were a statistically significant differences in Group D for all evaluated scores, in Group A for the urinary symptoms, pain and general health scores, and in Group B for the urinary symptoms, pain and sexual matters (Table 2).

There were statistical significances when we compared the percentage of improvement between Group $\mathrm{C}$ and the control group as regard to urinary symptoms, pain, general health and work performance ( $p 2$-values were $<0.001$ ), aslo there were significances between Group A and the control group according to urinary symptoms and pain ( $p 2$-value were 0.047 and 0.001 respectively), and there were values when comparing Group B with the control group in the urinary symptoms and pain scores ( $p 2$-value were $<0.001$ and 0.005$)$ (Table 2).

Table (1): Comparison between the characteristics of studied patients.

\begin{tabular}{llllll}
\hline Variables & Group A & Group B & Group C & Group D & $p$-value \\
\hline Number of patients & 27 & 26 & 28 & 26 & \\
Mean age (years) & $49.44 \pm 12.59$ & $46.65 \pm 13.05$ & $45.96 \pm 9.43$ & $48.81 \pm 10.73$ & 0.636 \\
Sex (Male: Female) & $14: 13$ & $13: 13$ & $15: 13$ & $13: 8$ & 0.478 \\
Indications of stent placement: & & & & & \\
$\quad$ URS & 12 & 13 & 11 & 13 & \\
PCNL & 4 & 3 & 4 & 5 & 0.992 \\
ESWL & 7 & 6 & 7 & 5 & \\
$\quad$ Ureterolithotomy & 4 & 4 & 6 & 3 & \\
\hline
\end{tabular}

Table (2): Comparison between different studied groups according to percentage of improvement and $p$-values.

\begin{tabular}{lllll}
\hline Score & Group A & Group B & Group C & Group D \\
\hline $\begin{array}{l}\text { Urinary symptoms: } \\
\text { \% of improvement }\end{array}$ & $11.52 \pm 14.38$ & $29.32 \pm 14.39$ & $45.0 \pm 14.50$ & $0.60 \pm 1.70$ \\
$p_{1}$ value & $<0.001$ & $<0.001$ & $<0.001$ & 0.083 \\
$p^{2}$ value & 0.047 & $<0.001$ & $<0.001$ & \\
Pain: & & & & \\
$\%$ of improvement & $13.52 \pm 15.19$ & $7.30 \pm 7.72$ & $47.56 \pm 11.35$ & $0.16 \pm 2.60$ \\
$p_{1}$ value & $<0.001$ & $<0.001$ & $<0.001$ & 0.782 \\
$p^{2}$ value & 0.001 & 0.005 & $<0.001$ & \\
General health: & & & & \\
$\%$ of improvement & $7.77 \pm 10.33$ & $2.18 \pm 6.67$ & $38.98 \pm 16.03$ & $2.58 \pm 6.81$ \\
$p_{1}$ value & $<0.001$ & 0.106 & $<0.001$ & \\
$p^{2}$ value & 0.100 & 0.841 & $<0.001$ & \\
Work performance: & & & & \\
$\%$ of improvement & $9.52 \pm 17.22$ & $5.79 \pm 13.18$ & $47.31 \pm 19.11$ & $0.89 \pm 8.94$ \\
$p_{1}$ value & 0.007 & 0.026 & $<0.001$ & 0.502 \\
$p^{2}$ value & 0.148 & 0.357 & $<0.001$ & \\
Sexual matters: & & & & \\
$\quad \%$ of improvement & $2.26 \pm 45.23$ & $8.25 \pm 13.50$ & $8.10 \pm 12.30$ & $0.77 \pm 7.20$ \\
$p_{1}$ & 0.307 & 0.005 & 0.003 & 0.480 \\
\hline
\end{tabular}




\section{Discussion}

The double-J or pigtail stent is a tube placed within the ureteral lumen in a retrograde or antegrade fashion in order to maintain its patency. Placement of indwelling ureteral stents has become routine in the management of a variety of urinary tract diseases. Stents prevent upper urinary tract obstruction, divert urine, allowing for faster tissue healing, and dilate the ureter, assisting in stone passage [6]

Leibovici and colleagues suggested that use of double-J stents can lead to several side effects and cause negative effects on quality of life. These authors found common symptoms such as urgency, frequency and dysuria $(55 \%, 50 \%$ and $40 \%$ respectively) [7]

In their study of 146 cases, Damiano and colleagues showed that discomfort due to stent $(37.6 \%)$ and irritative urinary symptoms $(18.8 \%)$ were the most common complications in cases with a ureteral stent [8]

Joshi and colleagues in a study on 62 patients found that irritative urinary symptoms, incontinence and hematuria were present in $78 \%$ of the patients in whom the double-J stent was applied. In more than $80 \%$ of these patients, pain related to the stent affects their daily lives. Sexual dysfunction was seen in 38\% and deterioration in work performance was seen in $58 \%$ [9]

This was corresponding with our findings. We reported that the urinary symptoms post-operative were found in $80 \%$ of our cases, discomfort was $85 \%$ of the cases, pain associated with stenting was in $76 \%$ of our cases, affection of work performance was in 50 of our cases, decline in general health was $46 \%$, and sexual performance deterioration was in $44 \%$ of patients.

Wang and his colleagues suggested that relaxation of bladder neck/prostatic smooth muscle setting a rationale behind using alpha blockers in overcoming ureteral stent symptoms [10].

Another mechanism was thought to be related to stent itself which may unmask or exacerbate preexisting subclinical detrusor overactivity setting a rationale behind using antimuscarinic agents to improve stent-related symptoms [11,12]

There are multiple strategies for managing stent complications include accurate stent indications, stenting maneuvers, stent design and use of medications. Many medical therapies have been tested, such as analgesics, anticholinergics and $\alpha$-blockers, to deal with the irritative symptoms and pain related with ureteral stents [13]

In the present study, we found that tamsulosin monotherapy controlled ureteral stent related symptoms. We recorded only significance with urinary symptoms and pain. Yakoubi et al., performed a meta-analysis showed that alpha-blockers were associated with a significant decrease in urinary symptoms ( $p$-value 0.005) Also similar result was a significant decrease in pain score ( $p$-value 0.0004$)$ [14].

Wang, et al., in a prospective randomized study comparing tamsulosin to placebo in 145 patients using (USSQ) reported that tamsulosin improved stent related urinary symptoms ( $p$-value $<0.0001)$ and significant decrease in pain using VAPS ( $p$ value $<0.0001)$ as compared to placebo, and they recommended its routine use [15]

Also Damiano et al., reported that administration of tamsulosin has a positive effect on stent related urinary irritative symptoms although this study was not double-blinded or placebo-controlled [16].

Along with the above mentioned o -blockers studies, similar trials were performed with regimens such as anticholinergics in the treatment of stent related symptoms. In the present study, solifenacin monotherapy controlled stent-related symptoms and pain and these results were of statistical significant value. Similarly, Lee et al., reported in a prospective, randomized, and placebo-controlled study that post-operative solifenacin use was effective and well tolerated for the treatment of LUTS, stent-related body pain, and hematuria [17]

Also we recorded in our study that the patients received anticholinergic showed no statistical significant differences in the general health score, the work performance score, and the sexual matters score. Many researchers studied the effect of others antimuscrinic agents in reducing the negative symptoms associated with double-J ureteral stent. Park et al. In a prospective randomized controlled study reported that tolterodine was significantly able to improve pain and urinary symptom index scores when compared with alfuzosin and placebo [18]

Our study showed that the combination therapy gave the best results in improvement of urinary symptoms in the form of (frequency, urgency, dysuria, urge incontinence, and post voiding dribbling), pain associated with double-J stents, general health of the patients during the period of stenting, and work performance states of the patients, the 
$p$-values of improvement in these scores were of statistical significances except for sexual matter, and when we compared the combination therapy with the placebo group and the mono therapy groups (tamsulosin or solifenacin), there were statistical significant values as regard to urinary symptoms, pain, general health, and work performance. Yan $\mathrm{H}$ et al., in a randomized controlled trials that referred to the use of a combination of antimuscarinics and alpha-blockers for the treatment of ureteral stent-related symptoms, a systematic review and meta-analysis was conducted. The conclusion of meta-analysis showed the beneficial effect of the combined use of antimuscarinics and alpha-blockers. The alpha-blockers may enhance the efficacy of the antimuscarinics, which is beneficial for the treatment of ureteral stent related symptoms [19].

\section{References}

1- HALEBLIAN G., KIJVIKAI K., De La ROSETTE J., et al.: Ureteral stenting and urinary stone management: A systematic review. J. Urol., 179: 424-430.3, 2008.

2- DELLIS A., JOSHI H.B., TIMONEY A.G., et al.: Relief of stent related symptoms: Review of engineering and pharmacological solutions. J. Urol., 184: 1267-72, 2010.

3- WANG C.J., HUANG S.W., CHANG C.H., et al.: "Effects of specific a-1A/1D blocker on lower urinary tract symptoms due to double-J stent: A prospectively randomized study," Urological Research, Vol. 37, No. 3, pp. 147-52, 2009.

4- LEE Y.J., HUANG K.H., YANG H.J., CHANG H.C., CHEN J. and YANG T.K. : "Solifenacin improves doubleJ stent-related symptomsin both genders following uncomplicated ureteroscopic lithotripsy", Urolithiasis, Vol. 41, pp. 247-52, 2013.

5- EL-NAHAS A.R., et al.: "Validation of the Arabic linguistic version of the Ureteral Stent Symptoms Questionnaire". Arab Journal of Urology, 12 (4): 290-3, 2014.

6- NABI G., COOK J., DOW J., et al.: Outcomes of stenting after uncomplicated ureteroscopy: Systematic review and meta-analysis. B.M.J., 334: 572, 2007.

7- LEIBOVICI D., COOPER A., LINDNER A., et al.: Ureteral stents: Morbidity and impact onquality of life. Isr. Med. Assoc. J., 7: 491-4, 2005.
8- DAMIANO R., OLIVA A., ESPOSITO T., et al.: Early and late complications of double pigtail ureteral stent. Urol. Int., 69: 136-40, 2002.

9- JOSHI H.B., STAINTHORPE A., MACDONAGH R.P., et al.: Indwelling ureteral stents: Evaluation of symptoms, quality of life and utility. J. Urol., 169: 1065-9, 2003.

10- WANG C., HUANG C. and CHANG C.: "Effects of tamsulosin on lower urinary tract symptoms due to doubleJ stent: A prospective study", Urologia Internationalis, 83: 66-9, 2009.

11- AGARWAL A., DHIRAAJ S., SINGHAL V., et al.: "Comparison of efficacy of oxybutynin and tolterodine for prevention of catheter related bladder discomfort: A prospective, randomized, placebo-controlled, doubleblind study", British Journal of Anaesthesia, 96: 377-80, 2006.

12- LIM K.T., KIM Y.T., LEE T.Y., et al.: "Effects of tamsulosin, solifenacin, and combination therapy for the treatment of ureteral stent related discomforts", Korean Journal of Urology, 52: 485-8, 2011.

13- UGUR K., BILAL E., MURAT T., et al.: Effectiveness of medical treatment in overcomingthe ureteral doubleJ stent related symptoms. Can. Urol. Assoc. J., December, 6 (6): E234-E237, 2012.

14. YAKOUBI R., LEMDANI M., MONGA M., et al.: Is There a Role for Alpha-Blockers in Ureteral Stent Related Symptoms? A Systematic Review and Meta-Analysis. Journal of Urology, 186: 928-34, 2011.

15-WANG C.J., HUANG S.W. , CHANG C.H., et al.: "Effects of specific-1A/1D blocker on lower urinary tract symptoms due to double-J stent: A prospectively randomized study", Urological Research, 37: 147-52, 2009.

16- DAMIANO R., AUTORINO R., De SIO M., et al.: "Effect of tamsulosin in preventing ureteral stent-related morbidity: A prospective study", Journal of Endourology, 22: 651-5, 2008.

17- LEE Y.J., HUANG K.H., YANG H.J., et al.: "Solifenacin improves double $\mathbf{J}$ stent related symptoms in both genders following uncomplicated ureteroscopic lithotripsy", Urolithiasis, 41: 247-52, 2013.

18- PARK S.C., JUNG S.W., LEE J.W., et al.: The effects of tolterodine extended release and alfuzosin for the treatment of double-J stent-related symptoms. Journal of Endourology, 23: 1913-7, 2009.

19- YAN H., LIANG ZHOU, XIANG CAI, et al.: Effects of a-Blockers, Antimuscarinics, or Combination Therapy in Relieving Ureteral Stent-Related Symptoms: A MetaAnalysis. J. Endourol., 29 (6): 650-6, 2015. 


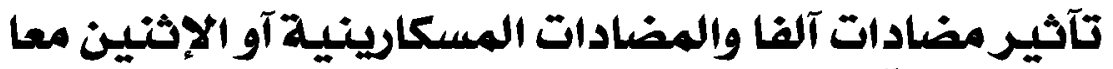

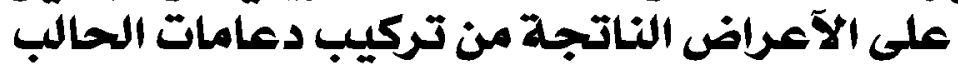

دعامة الحالب هي عبارة عن قسطرة يتم وضعها في الحالب للمحافظة على بقاء إتساع الحالب بعد جراحات المسالل البولية. وقد آصبح

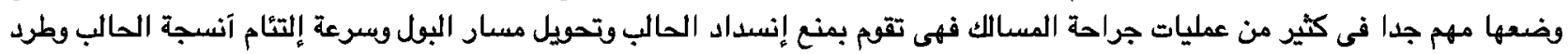

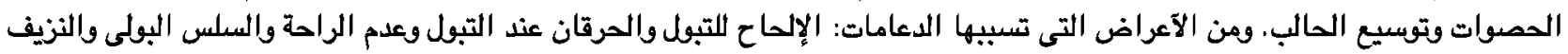

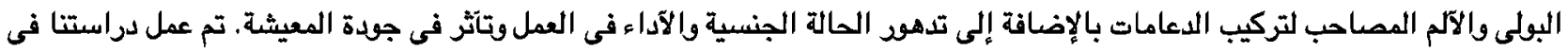

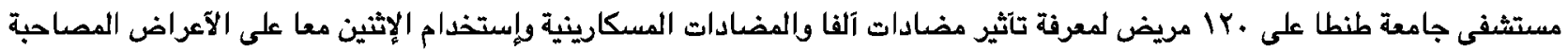
لتركيب دعامات الحالب. تم إختيار المرضى على حسب مان مواصفات خاصة حيث تم إختيار المرضى الخاضعين لعمليات في الحالب لآسباب

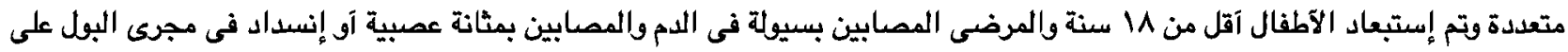

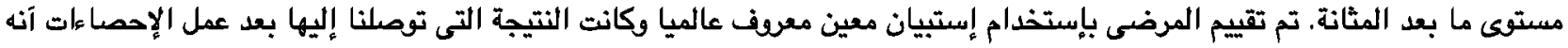

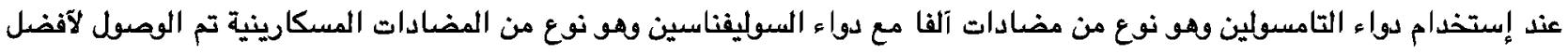

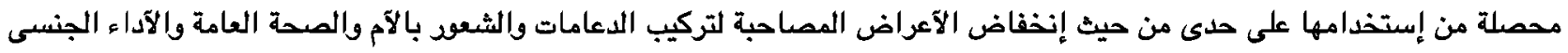
والآداء في العمل ومعتهى المعيشة. 